\title{
A Critical Analysis of Career Stress Among Academic Staff of Tertiary Institutions in Cross River State
}

\author{
${ }^{1}$ Ukwayi, Joseph. K. \\ ${ }^{2}$ Uko Esther S. \\ ${ }^{2}$ Udida, Lucy. A.
}

\author{
${ }^{1}$ Department of Sociology, University of Calabar.Email:jukwayi@yahoo.co.uk \\ ${ }^{2}$ Department of Educational Administration and Planning, University of Clabar
}

Doi:10.5901/jesr.2013.v3n2p15

\begin{abstract}
This paper attempt a critical analysis of career stress among academic staff of tertiary institutions in Cross River State. Information on career stress among academic staff were obtained in three institutions which include Cross River University of Technology (CRUTECH)), Cross River College of Education (COE) and University of Calabar (UNICAL). However, four hundred and fifty questionnaires were administered to senior lecturers in order to assess stress indicators among academic staff of tertiary intuitions in Cross River State. Two hypotheses were tested using the analysis of variance and the results show that there was no mean variation in the causes of career stress and challenges indicators among the three tertiary institutions under study in Cross River State. Besides, the data collected show that most academic staff suffered from series of symptoms during stress. Therefore, adequate incentive most be provided to academic staff to ensure productivity in their academic career.
\end{abstract}

Key Words: Academic, Career, Stress, staff, Symptom,

\section{Introduction}

In recent times, stress has become a major issue that has seriously affected academic staff tertiary institutions all over the world. However, scholars have come out with the view that stress in academic institutions can have positive and negative consequences if not properly controlled (Smith, 2002). Accordingly Edem (1982) in his analysis of stress pointed out that the task of a academic staff is always very complex. However, Nwadiani (2006) in affirming Edem(1982) view reveals the major indicators that give rise to stress to include irregular payment of salary, lack of adequate facilities, complex crises, lack of annual leave, lack of accommodation, high cost of living and research grant. Today, it has been observed that several researchers has shown that career stress has a negative effect on individual and organizational commitment especially when it comes to work performance (Cartwright, 2002). In Nigeria stress among academic staff of tertiary institutions is one of the factor that has disrupted smooth operation of academic activities in the tertiary institutions (Ogugua, 1987). Accordingly, several academic staff in Nigeria tertiary institutions have been observed to report insomnia, fear, hypertension, headaches, depression, adjustment disorders (emotional stress) as result of academic stree.These situation has cause wrong decision making, poor academic performance, lack of commitment and poor construction (Ikeotuonye, 1988). In Cross River State, the tertiary institutions such as Cross River State University of Technology, Cross River College of Education and the University of Calabar show that academic staff suffer from a lot of academic stress which occur as a result of trying to obtained a high percentage in their job performance. Besides, in most cases while trying to develop a research paper, preparing lecture notes for students and at the same time staying in an academic environment with no electricity and no access to internet , majority of academic staff who cannot survive under these condition are faced with stress which is the major concern of this work to assess career stress among academic staff of tertiary institutions in Cross River State with specific reference to assessing the socio-economic characteristics of academic staff, stress symptoms, 
causes of stress, challenges associated with career stress among academic staff of tertiary institutions in Cross River State.

\section{Methodology}

This study was conducted in Cross River State taking into consideration three tertiary institutions, namely Cross River University of Technology (CRUTECH) Cross River College of Education (COE) and University of Calabar (UNICAL). Four hundred and fifty copies of questionnaire were distributed to the various institution of which one fifty copies of questionnaire were administered to each institution using stratified sampling technique. The rationale for using stratified sampling technique was based on the fact that the targeted population were the academic staff in the rank of senior lecturer and above. The questionnaires captured information such as stress symptoms, stress indicators (causes) and the challenges associated with stress. However, the analysis variance (ANOVA) was used in testing the two stated hypotheses which try to investigate if or not there was a significant variation in the causes of stress and challenges among academic staff in the three tertiary institutions in Cross River State.

\section{Literature review}

Today, many scholars in behavior studies attribute poor health is an outcome of stress, and it can be used to ascertain if workplace pressures have positive and motivating or negative and damaging effects. However, poor health may not necessarily be indicative of workplace stress. Individuals may, for example, be unwell because they choose not to lead a healthy lifestyle or may be unaware of how to do so (Cartwright \& Cooper, 2002). It has been observed that certain studies found high levels of stress relating to work relationships, control, resources and communication and job insecurity (See Tytherleigh, 2003; Tytherleigh, et al, 2005), excessive overload and work life imbalance are among the most frequently reported stressors by academics (Association of University Teachers, 2003). In fact, 80 percent of the academics in Boyd and Wylie's (1994) study indicated that their workloads had expanded significantly in recent years. The recent escalation in the demands of the job, it is not surprising that academic staff report difficulty in maintaining firm boundaries between the workplace and the home as, for many, it appears that the home is the extension of the workplace (Kinman, 1998). A high number of academics (67\%) that the home is the extension of the work now encroached more on their home lives than in the recent past and 72 percent believed that their families suffered as a direct result of their jobs. More seriously, both work overload and work-life imbalance have been related to low psychological well-being among academics (Daniels \& Guppy, 1994; Kinman \& Jones, 2003; Winefield, et al, 2002).Today, it has been observed that, the psychological well-being amongst academics is relatively poor (see Kinman, 2001). Accordingly, majority of the respondents in Gillespie, et al's (2001) study reveal that stress impacted on them psychologically: they describe experiencing feelings of anxiety, depression, burnout, anger, irritability and helplessness. Accordingly (Watt, et al, 1991), depression has been associated with suicidal thoughts and in fact, an epidemiological study of suicide conducted by Kelly, Charlton and Jenkins (1995) suggest that university academic staff are at around 50 percent greater risk than the average worker. Psychological stress, in turn, can lead to severe physical consequences. Winefield, et al (2002). In empirical study reported that, the majority of the respondents reported experiencing tiredness 'sometimes' to 'nearly all the time', back and neck pains, sleeping difficulties, headaches, muscle pain, colds and virus infections. Furthermore, in the South African context, Coetzee and Rothman (2005) recently found high levels of psychological and physical ill health in a sample of 372 university staff members. Today, it has been noticed that none commitment among academics remain confusing and confounding. There is some evidence to suggest that, on average, academic staff appear to be committed to their organizations while experiencing stressors and strains (McInnis, 1999; Winefield, et al, 2002). However, in the latter study, the strongest predictor of staff commitment to the university was trust in senior management. Similarly, Meyer and Allen (1997) also suggested that the organization's support to academics explained their emotional commitment towards their universities. Interestingly, Coetzee and Rothman (2005) found that while university staff member were committed to their institutions, they perceived a lack of commitment from their employer. In addition, Millward-Brown (1996) found that university and college lecturers reported lower levels of perceived commitment from their organization when they were compared 
with 20 other occupational groups. Furthermore, Tytherleigh, et al (2005) found that all higher education staff reported significantly lower levels of commitment both from and to their organization. However, despite the low commitment levels, staff members still experience low levels of stress relating to home-work balance, overload, the job overall and physical ill health. Chui and Kosinski (1995) argued that organizational commitment , as an attitudinal variable, influences stress. Similarly, Sommer, Bae and Luthans (1996) contended that organizational commitment is one of the important variables in the study of employee behaviour since it is inversely related. However, D'Arcy (2007) emphasizes that everyone experiences stress a little differently, it can be a good thing, but overload of it is a different story. He explains that stress overload is caused by the overreaction or failure of the stress response to turn off and reset itself properly. Health and Safety Executive (HSE) (2001) defined stress as the adverse reaction a person has to excessive pressure or other types of demand placed upon them. They maintain that stress affects us in different ways at different times and is often the result of a combination of factors in our personal and working lives, and that stress is not a weakness but if unnoticed it can lead progressively to a decrease in performance, poor health and long term absence from work. Winifred (2000) indicates that there is prevalence of career stress among non-academic staff of universities. Studies by Awopegba (2001), Lam and Punch (2001) and Boyd and Wylie (1994) are in support of stress among academic staff of universities. Indeed, in the clamour for university education and with each university determined to achieve its goal, the academic staff are bound to be stressed. Furthermore, Ahsan, Abdullah, Fie and Alam (2009) pointed out stress inducing factors in academic staff to include: work overload, homework interface, role ambiguity and performance pressure. In support of stress on academic staff, Abouserie (1996) found workload as factors of stress. Listing the most related stressors on academic staff, Ahmandy, Changiz, Masiello and Bromnels (2007), included workload, conflict, demands from colleagues and supervisors, incompatible demands from different personal and organization roles, inadequate resources for appropriate performance, insufficient competency to the demands of their role, inadequate autonomy to make decision on different tasks and feeling of underutilization. Ofoegbu and Nwadiani (2006) reveals important factors influencing stress among non-academic staff to include strike and school interruption, delay and irregular payment of salary, lack of instructional facilities, campus militancy, high cost of living, office accommodation, lack of anneal leave/holiday and underfunding of education. Management role expectations and home work interface was identified of Alexandros -Stamatios, Matilyn and Cary (2003). Additional sources of academic stress identified in studies by Rutter, Hezberg and Paice (2002) in their study, another source of stress to include high self expectation, securing financial support, insufficient development in the field, inadequate salary, manuscript preparation, role overload, conflicting job demands, slow progress on career advancement, frequent interruptions and long meetings as causes of stress among non-academic staff. Working conditions, poor motivation, external factors and low status were identified by Lam and Punch (2001) and Boyd and Wylie (1994). Arguing, Blix, Cruise, Mitchell and Blix (1994) posited that limited resources and shortage of time, slow progress in career advancement, poor faculty communication, professional disillusionment and inadequate salaries were directly related to pressure experienced by academic staff. Goldenberg and Waddell (1990) insisted that heavy work load, role ambiguity, conflicting job demands, frequent interruption and publication efforts were causes of stress on academic staff. In study by higher level of stress were reported as arising from funding cuts to universities, heavier teaching loads, difficulty in securing research funds, lack of resources, poor relationship with colleagues and unrealistic expectations from management by Winfried and Jarret (2001) and Ahmady, et al (2007). On gender, level of stress were found not to be different among male and female non-academic staff by Abouserie (1996) and Ofoegbu and Nwadiani (2006). However, Liu and Zhu (2009) found that female nonacademic staff experience less stress than their male counterparts. However, several theories have been used to support this research which including the physiological theory of stress and development stress theory. However, even though much have been done in this area none has highlighted the subject matter with respect to the three institutions in Cross River State which is the gap that this work intend to bridge in the existing literature

\section{Findings}

\subsection{Socio-economic characteristics of non-academic staff in tertiary institution}


The socio-economic characteristics of the academic staff in the tertiary institutions presented in table 1 show that $56 \%$ of the respondents used for this study were male while only $43 \%$ were female. More so, $40,7 \%$ and $28,7 \%$ sampled academic staffs in the various institutions were married and widowers while only $19 \%$ and $11 \%$ were widow and single. Furthermore, $44,7 \%$ and $24,2 \%$ constitute the sampled population of those who are up to $25 y e a r s$ and 35 years and above. This means that the population of academic staff of the tertiary institutions in Cross River State are those within the age brackets of $25 y e a r s$ and 35 years and above

Table 1: Socio-economic characteristics of academic staff in tertiary institutions

\begin{tabular}{|c|l|c|c|}
\hline S/n & Sex & Frequency & Percentage \\
\hline A & Male & 253 & 56.2 \\
\hline B & Female & 197 & 43.8 \\
\hline & Total & 450 & 100 \\
\hline S/n & Marital status & Frequency & Percentage \\
\hline A & Widower & 129 & 28.7 \\
\hline B & Single & 50 & 11 \\
\hline C & Married & 183 & 50.9 \\
\hline D & Widow & 88 & 19.6 \\
\hline & Total & 450 & 100 \\
\hline S/n & Age (years) & Frequency & Percentage \\
\hline A & $1-15 y r s$ & 42 & 9.3 \\
\hline B & $15-25 y r s$ & 201 & 21.2 \\
\hline C & $25-35 y r s$ & 98 & 24.2 \\
\hline D & 35 and above & 109 & 100 \\
\hline & Total & 450 & \\
\hline
\end{tabular}

Source: Field survey, 2012

\subsection{Stress symptoms in tertiary institutions}

The stress symptoms among academic staff of tertiary institutions in Cross River State presented in table 2 show that headaches, poor concentration and tiredness were the major stress symptoms associated with academic staff of tertiary institutions in Cross River State with values of $15.55 \%$ and $14.66 \%$. Table 2 indicates that career stress symptoms can generated job dissatisfaction and anxiety as observed in the sampled population with a values of $9.77 \%$ and $9.11 \%$ while indecision and insomnia were on the least side with a value of $6,4 \%$ and $6 \%$. However, table 2 also show that over $15.55 \%$ and $13.33 \%$ of the sampled population also claimed that dizziness and body pains are stress symptoms that have affected academic staff of tertiary institutions in Cross River State

Table 2: Stress symptoms among academic staff of tertiary institutions

\begin{tabular}{|l|c|c|c|c|c|}
\hline \multirow{2}{*}{ Symptoms of stress } & \multicolumn{3}{|c|}{ Tertiary institutions } & \multirow{2}{*}{$\%$} \\
\cline { 2 - 5 } & CRUTECH staff & UNICAL staff & COE staff & Total & \\
\hline Body pains & 21 & 24 & 25 & 70 & 15.55 \\
\hline Headaches & 18 & 17 & 13 & 48 & 10.66 \\
\hline Job satisfaction & 15 & 13 & 16 & 44 & 9.77 \\
\hline Anxiety & 14 & 15 & 12 & 41 & 9.11 \\
\hline Poor concentration & 22 & 23 & 21 & 66 & 14.66 \\
\hline Indecision & 8 & 10 & 11 & 29 & 6.44 \\
\hline Tiredness & 23 & 22 & 20 & 65 & 14.44 \\
\hline Insomnia & 9 & 11 & 7 & 27 & 6.00 \\
\hline Dizziness & 20 & 15 & 25 & 60 & 13.33 \\
\hline Total & 150 & 150 & 150 & 450 & 100 \\
\hline
\end{tabular}

Source: Field survey, 2012 


\subsection{Stress indicators (causes)}

The causes of stress as presented in figure 1 indicate that high cost of living and inadequate facilities were the main causes of stress among academic staff of tertiary institutions in Cross River Stat followed by conflicting job demands and poor relationship with colleagues. Although, it was noticed in figure 1 that lack of annual leave was another major causes of stress with a value of $12.22 \%$ while lack of resources and workload were on the least side with a value of $8 \%$ and $7 \%$ which show that two indicators were insignificant and does not contribute to stress among academic staff in tertiary institutions in Cross River State.

Figure 2: Causes of stress among academic staff in tertiary institutions

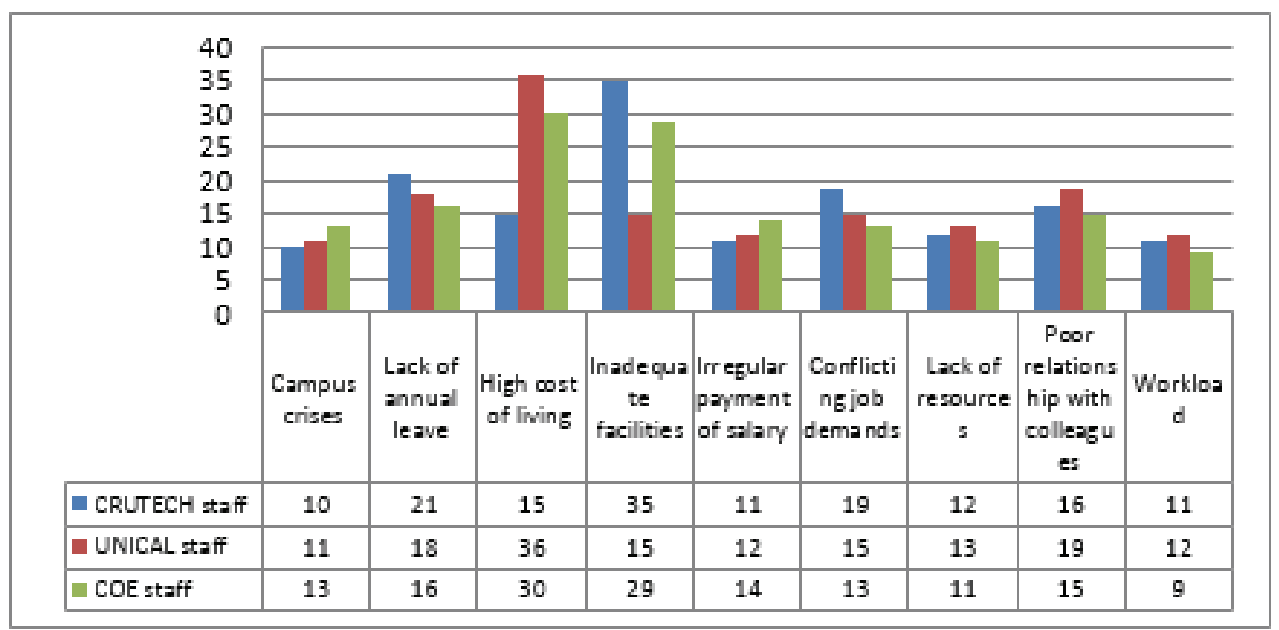

Source: Field survey, 2012

\subsection{Challenges associated with career stress}

The challenges associated with career stress among academic staff of tertiary institutions in Cross River State presented in table 3 revealed that over $24.22 \%$ and $23.11 \%$ of the sampled population in the tertiary institutions in Cross River State were with the opinion that the major challenges of career stress among academic staff were employee performance and reduction in productivity. Though, over $10.88 \%$ and $10.66 \%$ were with the opinion that health problems and absenteeism were also challenges associated with career stress among academic staff of tertiary institutions in Cross River State.

Table 3: Challenges associated with career stress

\begin{tabular}{|l|c|c|c|c|c|}
\hline \multirow{2}{*}{ Symptoms of stress } & \multicolumn{3}{|c|}{ Tertiary institutions } & \multirow{2}{*}{$\%$} \\
\cline { 2 - 5 } & CRUTECH staff & UNICAL staff & COE staff & Total & \\
\hline $\begin{array}{l}\text { Reduce employee } \\
\text { performance }\end{array}$ & 40 & 39 & 30 & 109 & 24.22 \\
\hline Poor quality control & 18 & 19 & 20 & 57 & 12.66 \\
\hline $\begin{array}{l}\text { Reduction in } \\
\text { productivity }\end{array}$ & 36 & 35 & 33 & 104 & 23.11 \\
\hline Health problems & 16 & 18 & 15 & 49 & 10.88 \\
\hline Absenteeism & 18 & 16 & 14 & 48 & 10.66 \\
\hline Total & 150 & 150 & 150 & 450 & 100 \\
\hline
\end{tabular}

Source: Field survey, 2012 
The analysis result for the causes of stress among academic staff in tertiary institutions presented in table 4 show that a calculated value (0) is less than the critical value (2.59) at degree of freedom 26 which was tested at 0.05 level of significance, the null hypothesis $(\mathrm{Ho})$ which state that "there is no variation in the causes of stress among the three tertiary institutions in Cross River State this result indicate that all the model variables constitute the major causes of academic stress in all the three institutions

Table 4 Analysis of variance on the causes of Careers tress in tertiary institutionsIn Cross River State

\begin{tabular}{|l|c|c|c|c|c|}
\hline Source of variance & Sum of square & Cal. Value & Df & $\begin{array}{c}\text { Mean sum of } \\
\text { square }\end{array}$ & $F$ \\
\hline Between sample size & 0.1 & & 2 & 0.1 & \\
\hline Within sample & & 0 & & & 2.59 \\
\hline Mean & 268.3 & & 24 & 11.179 & \\
\hline Total & 268.3 & & 26 & & \\
\hline
\end{tabular}

Source: Data analysis, 2012

Furthermore, the result of the hypothesis which try to ascertained whether or not there was a variation in the challenges of career stress in the three tertiary institutions presented in table 5 show a calculated value of 0.1 is less than the critical value (2.81) at 0.05 level of significant. The result above affirmed the first hypothesis which at the same time means that all the aforementioned indicators constitute the problems in the three institutions in Cross River State.

Table 5: Analysis of variance on the challenges of career stress in tertiary institutions

\begin{tabular}{|l|c|c|c|c|c|}
\hline Source of variance & Sum of square & Cal. Value & Df & $\begin{array}{c}\text { Mean sum of } \\
\text { square }\end{array}$ & $\mathrm{F}$ \\
\hline Between sample size & 0 & & 2 & 0 & \\
\hline Within sample & & 0 & & & 2.81 \\
\hline Mean & 600.3 & & 15 & 40 & \\
\hline Total & 600.3 & & 17 & & \\
\hline
\end{tabular}

Source: Data analysis, 2012

\section{Recommendations}

This study which tries to investigate career stress among academic staff of tertiary institutions in Cross River State indicate that stress has constituted a major challenge in job performance among academic staff of tertiary institutions in the area. To this end, the following recommendations are hereby put forward to help avert the challenges of career stress among academic staff in tertiary institutions in the state.

$>$ The authorities concern should provide adequate incentives that would enhance academic excellence

$>$ Academic staff should be exposed to research grants to enable them conduct good academic researches

> Adequate facilities should be provided in their place of work to enhance work performance

$>$ The authorities concern should make sure that workload are reduced to academic staff so has to increase efficiently in work performance

\section{Conclusion}

Today, the poor and uncondusive learning environment has expose academic staff to serious stress. This situation has given rise to low productivity, inefficiently and lack of adequate commitment in job performance. The above statement was evidenced in the data collected which show a high rate of career stress among academic staff in the tertiary institution in Cross River State. It is on this note that effective measures must be put in place to reduce academic stress in tertiary institution in Cross River State. 


\section{References}

Allen, T. D., Herst, D. E., Bruck, C. S., \& Sutton, M. (2000). Consequences associated with work-to-family conflict: a review and agenda for future research. Journal of occupational health psychology, 5, 278-308.

Association of University Teachers (2003). Survey of members. London: AUT.

Cartwright, S., \& Cooper, C. L. (2002). Asset: An organizational stress screening Tool- The management guide. Manchester, UK: RCL Ltd.

Chui, R. K., \& Kosinski, F. A. Jr (1995). Chinese cultural collectivism and work-related stress: implications of employment counselors. Journal of industrial psychology, 31, 47-54.

Daniels, K. \& Guppy, A. (1994). An exploratory study of stress in a British University. Higher Education quarterly, 48, 135-144.

Gillespie, N. A., Walsh, M., Winefield, A. H, Dua, J. \& Stough, C. (2001). Occupational stress in universities: Staff perceptions of the causes, consequences and moderators of stress. Work \& stress, 15, 53-72.

Kinman, G. (1998). Pressure points: A survey into the causes and consequences of occupational stress in the UK academic and related staff. London: Association of University Teachers.

Kinman, G. (2001) Pressure points: A review of research on stressors and strains in UK academics.

Kinman, G. \& Jones, F. (2003). Running up and down the escalator: stressors and strains in UK academics.

McInnis, C. (1999). Change and diversity in work patterns of Australian academics. Higher education management, 105117.

Meyer, J. P., \& Allen, N. J. (1997). Commitment in the workplace: Theory, research and application. Thousand oaks, CA: Sage.

Milward-Brown (1996). Powerful people: A survey of Britain's professional workforce. London: Guardian publishing.

Sommer, S. M., Bae, S. \& Lithans, F. (1996). Organizational commitment across cultures: The impact and antecedents on Korean employees. Human relations, 49, 977-993.

Tytherleigh, M. Y., Webb, C., Cooper, C. L. \& Ricketts, C. (2005). Occupational stress in UK higher education institutions: A comparative study of all staff categories. Higher education research \& development, 1, 41-61.

Winefield, A. H., Gillespie, N., Stough, C., Dua, J. \& Hapuararchchi, J. (2002). Occupational stress in Australian universities: A national survey. Melbourne: National tertiary education opinion. 
